\title{
High Thermal Conductivity and Anisotropy Values of Aligned Graphite Flakes/Copper Foil Composites
}

\author{
Fankun Zeng ${ }^{1} \mathbb{D}$, Chen Xue ${ }^{1,2, *}$, Hongbing Ma ${ }^{1}$, Cheng-Te Lin ${ }^{1,2} \mathbb{D}$, Jinhong Yu ${ }^{1,2, *(\mathbb{D})}$ and \\ Nan Jiang $1,2, *$
}

1 Key Laboratory of Marine Materials and Related Technologies, Zhejiang Key Laboratory of Marine Materials and Protective Technologies, Ningbo Institute of Materials Technology and Engineering (NIMTE), Chinese Academy of Sciences, Ningbo 315201, China; zengfankun@nimte.ac.cn (F.Z.); mahongbing@nimte.ac.cn (H.M.); linzhengde@nimte.ac.cn (C.-T.L.)

2 Center of Materials Science and Optoelectronics Engineering, University of Chinese Academy of Sciences, Beijing 100049, China

* Correspondence: xuechen@nimte.ac.cn (C.X.); yujinhong@nimte.ac.cn (J.Y.); jiangnan@nimte.ac.cn (N.J.); Tel.: +86-574-8668-5165 (C.X. \& J.Y.); +86-574-8761-5701 (N.J.)

Received: 21 November 2019; Accepted: 18 December 2019; Published: 20 December 2019

\begin{abstract}
Much attention has been paid to graphite flakes/copper $(\mathrm{GFs} / \mathrm{Cu})$ composites for thermal management due to their remarkable thermal properties. Most studies focus on the interface interaction between GFs and $\mathrm{Cu}$ in composites. However, controlling the orientation of GFs still remains a challenge. Herein, we report a reliable method to ensure consistent orientation of GFs in the composites. Firstly, the disorder GFs were well arranged on the surface of copper foil by tape casting process in the casting machine. Then highly aligned GFs/Cu composites were fabricated by hot pressing process in a vacuum hot-pressing furnace, with the volume fraction of graphite from $30 \%$ to $70 \%$. The SEM images show that the obtained GFs/Cu composites presented a layer-by-layer structure or network structure with a different content of GFs. The thermal conductivity of GFs/Cu composites exhibited an extreme anisotropy due to the highly aligned GFs. The ultrahigh thermal conductivity of GFs/Cu composites with $70 \mathrm{vol} \%$ GFs reached $741 \mathrm{~W} /(\mathrm{m} \cdot \mathrm{K})$, while through-plane thermal conductivity was just $42 \mathrm{~W} /(\mathrm{m} \cdot \mathrm{K})$. The alignment of GFs and interfacial thermal resistance were deeply analyzed and a thermal conductivity model for GFs/Cu composites was established. Our work provides a new idea to significantly enhance the thermal transportation performance of $\mathrm{GFs} / \mathrm{Cu}$ composites by well controlled alignment of GFs in $\mathrm{Cu}$ matrix.
\end{abstract}

Keywords: alignment of graphite flakes; copper; thermal conductivity; hot press process

\section{Introduction}

In recent years, heat sink materials with high thermal conductivity (TC) have become increasingly important, especially in packaging electronic chips and devices with high power density which produce much heat to dissipate [1,2]. Owing to good thermal and mechanical properties, Al with a TC of $237 \mathrm{~W} /(\mathrm{m} \cdot \mathrm{K})$ and $\mathrm{Cu}$ with a TC of $400 \mathrm{~W} /(\mathrm{m} \cdot \mathrm{K})$ are frequently used as the raw materials of heat sinks and heat spreaders in order to transfer heat from electronic devices to outside equipment $[3,4]$. However, the heat dissipation of $\mathrm{Al}$ cannot match the requirements of modern power electronics and $\mathrm{Cu}$ is too heavy to be used in integrated and miniaturized electronic devices. Carbon-based materials (e.g., graphene [5,6], graphite flakes [7,8], carbon nanotubes [9], carbon fibers [10], and diamond [11], etc.) are promising conductive fills due to their high TC. The 1D carbon nanotubes, which are typical nano carbon materials, have quoted values of $\sim 3500 \mathrm{~W} /(\mathrm{m} \cdot \mathrm{K})$ with single-walled structures and $\sim 3000 \mathrm{~W} /(\mathrm{m} \cdot \mathrm{K})$ with multi-walled structures in axial directions at room temperature $[12,13]$. 
The TC of carbon fibers reaches $1000 \mathrm{~W} /(\mathrm{m} \cdot \mathrm{K})$ in the longitudinal direction [14], which is lower than carbon nanotubes due to the increase in size. The 2D graphene exhibits a high TC in the range of $1500 \sim 5300 \mathrm{~W} /(\mathrm{m} \cdot \mathrm{K})$ at room temperature, depending on the defects and thickness [15,16]. The in-plane ultimate maximum TC of graphite is approximately $2000 \mathrm{~W} /(\mathrm{m} \cdot \mathrm{K})[17,18]$. The 3D diamond, the hardest matrials in nature, are considered perfect thremal and mechanical reinforcements with TC in a range from 1200 to $2000 \mathrm{~W} /(\mathrm{m} \cdot \mathrm{K})[19,20]$.

Nowadays, carbon-based materials to reinforce metal matrix composites show promise for thermal management. However, the distribution and alignment of nanoscale carbon-based materials (e.g., graphene and carbon nanotubes, etc.) remain big challenge to researchers, limiting the content of conductive fills in composites [21]. Diamond/metal matrix composites draw much attention due to excellent thermal properties, with isotropic TC approaching $600 \mathrm{~W} /(\mathrm{m} \cdot \mathrm{K})$ [22]. Nevertheless, the high price of diamonds and the lack of easy processability precludes the using of these composites from a wide range of technological applications. In view of this, graphite flakes (GFs)/Al and GFs/Cu composites have attracted much interest from researchers, with high TC, low cost, good mechanical properties and processability. It is reported that interface bonding significantly affects the TC and mechanical properties of GFs/metal composites, due to bad wettability of GFs and metals. Xue et al. [8] reported that a silicon carbide nano-layer coated on the GFs' surface could increase interface bonding of GFs/Al composites. The in-plane TC and flexural strength of GFs/Al composites increased from $505 \sim 702 \mathrm{~W} /(\mathrm{m} \cdot \mathrm{K}), 46 \sim 24 \mathrm{MPa}$ to $528 \sim 735 \mathrm{~W} /(\mathrm{m} \cdot \mathrm{K}), 90 \sim 45 \mathrm{MPa}$, respectively, as the volume fraction of GFs increased from $40 \%$ to $70 \%$. Bai et al. [23] reported that a boron carbide nano-layer on the graphite surface realized by salt bath process could promote flexural strength of GFs/Cu composites from $94 \sim 52 \mathrm{MPa}$ to $145 \sim 74 \mathrm{MPa}$, as the volume fraction of GFs was $40 \%$ to $70 \%$. Howerer, the in-plane TC of GFs/Cu composites decreased from $477 \sim 676 \mathrm{~W} /(\mathrm{m} \cdot \mathrm{K})$ to $449 \sim 608 \mathrm{~W} /(\mathrm{m} \cdot \mathrm{K})$. A silicon carbide nano-layer on GFs surface could also enhance interface bonding of GFs/Cu composites, with flexural strength increasing from 94 52 MPa to 110 75 MPa [24]. Nevertheless, the in-plane TC decreased from $474 \sim 676 \mathrm{~W} /(\mathrm{m} \cdot \mathrm{K})$ to $460 \sim 610 \mathrm{~W} /(\mathrm{m} \cdot \mathrm{K})$, similar to carbide-boron nano-layer coated GFs/Cu composites. Although coatings of the boron carbide nano-layer and silicon carbide nano-layer were of benefit to interface bonding of GFs/Cu composites, they may not be of benefit to TC. Liu et al. [25] fabricated $71 \mathrm{vol} \%$ of GFs/Cu composites using a sparking plasma sintering after $\mathrm{Cu}$ coated on GFs by electroless plating process and improved TC to $565 \mathrm{~W} /(\mathrm{m} \cdot \mathrm{K})$. However, the value of TC was too low. Some researchers have disscussed the effect of shape or average size, volume fraction, and alignment of GFs on the TC of GFs/metal composites. Sohn et al. [26] reported that the TC of GFs/Cu composites fabricated by hot-pressing method reached $456.9 \mathrm{~W} /(\mathrm{m} \cdot \mathrm{K})$ with $59 \mathrm{vol} \%$ of GFs, which was approximately twice that of granules/Cu composites (a TC of $244.5 \mathrm{~W} /(\mathrm{m} \cdot \mathrm{K})$ ). Zhou et al. [27] reported that the TC of GFs/Al composites with an average size of $500 \mu \mathrm{m}$ reached $400 \mathrm{~W} /(\mathrm{m} \cdot \mathrm{K})$ with $50 \mathrm{vol} \%$ of GFs, while GFs/Al composites with an average size of $100 \mu \mathrm{m}$ were about $320 \mathrm{~W} /(\mathrm{m} \cdot \mathrm{K})$. As the content of GFs with an average size of $500 \mu \mathrm{m}$ reached $60 \%$, the TC of GFs/Al composites reached $530 \mathrm{~W} /(\mathrm{m} \cdot \mathrm{K})$. Li et al. [28] provided a process to prepare highly aligned GFs/Al composites with different sizes of GFs by squeeze casting. As the average size of GFs increased from $150 \mu \mathrm{m}$ to $495 \mu \mathrm{m}$, the in-plane TC increased from 548 to $664 \mathrm{~W} /(\mathrm{m} \cdot \mathrm{K})$. The TC of $\mathrm{GFs} / \mathrm{Al}$ composites amazingly reached $714 \mathrm{~W} /(\mathrm{m} \cdot \mathrm{K})$, as the average size of GFs was $495 \mu \mathrm{m}$ and volume fraction was $70 \%$. Highly aligned GFs/Al composites exhibited great potential for heat dissipation. However, the fabrication process of the composites is very complicated for industrial production.

In this work, we focus on the preparation of GFs/Cu composites with ultrahigh TC. Considering the anisotropic TC of GFs, novel strategies for controlling the alignment of GFs in the copper matrix are successfully developed. Copper foil is firstly introduced into GFs/Cu composites, replacing the easily oxidized $\mathrm{Cu}$ powders. Not only is copper foil in the metal matrix, but also the basis of aligned GFs. The in-plane TC of GFs/Cu composites increases from 503 to $741 \mathrm{~W} /(\mathrm{m} \cdot \mathrm{K})$, as the volume fraction of GFs is 30 70\%. The alignment of GFs, microstructures, interfaces and TC modeling are thoroughly discussed. The fabrication process with our approach is scalable and is easy used in 
industry. The advanced GFs/Cu composites can be realized to help cool modern electronics in the near future.

\section{Materials and Methods}

\subsection{Materials and Reagents}

Commercial graphite flakes (GFs) with an average in-plane size of $500 \mu \mathrm{m}$ and thickness of $50 \mu \mathrm{m}$ were supplied by Qingdao haida Graphite Co., Ltd. (Qingdao, China). The copper foil with a purity of $>99.9 \%$, having a series size of $6,15,50$ and $100 \mu \mathrm{m}$, were provided by Jiangxi Copper Co., Ltd. (Nanchang, China). The polyvinyl butyral (PVB) with a purity of $>99.9 \%$ was purchased from Sinopharm Chemical Reagent Co., Ltd. (Shanghai, China). The other reagents used in the electroless plating and tape casting process are commercial products.

\subsection{Cu Coating Grown on the Surface of GFs}

In order to improve the interfacial strength between GFs and $\mathrm{Cu}$, a $\mathrm{Cu}$ coating was grown on the surface of the GFs by electroless plating method [25,29]. The main steps of electroless plating procedures are introduced as follows: (i) The GFs are put into $600 \mathrm{~mL} / \mathrm{L} \mathrm{H}_{2} \mathrm{SO}_{4}$ solution and stirred in the water bath with a speed of $80 \mathrm{r} / \mathrm{min}$ at $60^{\circ} \mathrm{C}$ for $60 \mathrm{~min}$; (ii) The GFs are treated by an ultrasonic instrument with the mixture of $20 \mathrm{~g} / \mathrm{L} \mathrm{SnCl}_{2}$ solution and $60 \mathrm{~mL} / \mathrm{L} \mathrm{HCl}$ solution for $20 \mathrm{~min}$ at room temperature; (iii) Continuing ultrasonic process with the mixture of $0.3 \mathrm{~g} / \mathrm{L} \mathrm{PdCl}_{2}$ solution and $5 \mathrm{~mL} / \mathrm{L}$ $\mathrm{HCl}$ solution for $20 \mathrm{~min}$ in room temperature; (iv) The pretreated GFs are put into the mixture solution of $50 \mathrm{~g} / \mathrm{L} \mathrm{CuSO}{ }_{4}, 15 \mathrm{~g} / \mathrm{L} \mathrm{Zn}$ and $10 \mathrm{~mL} / \mathrm{L}$ and stirred in the water bath at a speed of $150 \mathrm{r} / \mathrm{min}$ at $40{ }^{\circ} \mathrm{C}$ for $60 \mathrm{~min}$. The GFs were cleaned with pure water at the end of each step above. (v) The treated GFs were dried by the electric vacuum drying oven at $80^{\circ} \mathrm{C}$.

\subsection{Tape Casting Process}

The GFs were well arranged on the surface of copper foil by tape casting process. The PVBethanol solution (the mass ratio of PVB and ethanol absolute was 1:7) was pre-mixed using a mixer at a speed of $150 \mathrm{r} / \mathrm{min}$ for $10 \mathrm{~min}$. Then Cu coated GFs were put into the PVB-ethanol solution mixed at a speed of $200 \mathrm{r} / \mathrm{min}$ for $20 \mathrm{~min}$ and we then obtained the slurry for the tape casting process. The slurry was cast on the surface of $6 \mu \mathrm{m}$ copper foil with a limited height of $60 \mu \mathrm{m}$ controlled by a blade and pressed by a rubber roller. After that, it was dried at $80^{\circ} \mathrm{C}$ for $5 \mathrm{~min}$, and we obtained a special GFs-Cu layer that aligned $\mathrm{Cu}$ coated GFs coated on copper foil. The volume fraction of GFs in a single GFs-Cu layer was about $90 \%$ in reality.

\subsection{Preparation of $\mathrm{GFs} / \mathrm{Cu}$ Composites}

The graphite flakes/copper foil (GFs/Cu) composites were prepared by hot-pressing process with the volume fraction of GFs ranging from $30 \%$ to $70 \%$. To obtain the GFs/Cu composites with different content of GFs, the extra copper foil was put between two GFs-Cu layers (e.g., one layer of $100 \mu \mathrm{m}$ copper foil for $30 \mathrm{vol} \% \mathrm{GFs} / \mathrm{Cu}$ composites, three layers of $15 \mu \mathrm{m}$ copper foil for $30 \mathrm{vol} \% \mathrm{GFs} / \mathrm{Cu}$ composites and two layers of $6 \mu \mathrm{m}$ copper foil for $70 \mathrm{vol} \% \mathrm{GFs} / \mathrm{Cu}$ composites). A number of GFs-Cu layers and copper foil were stacked into a graphite mold in turn with a layer-by-layer structure and sintered in the vacuum hot press furnace at $1040^{\circ} \mathrm{C}$ and $40 \mathrm{MPa}$ for $2 \mathrm{~h}[24,26]$. The volume ratio was mainly controlled by adding different copper foil between two GFs-Cu layers and the calculation deviation of GFs volume fraction was $5 \%$. The complete preparation process of aligned graphite/Cu composites was showed in Figure 1. 


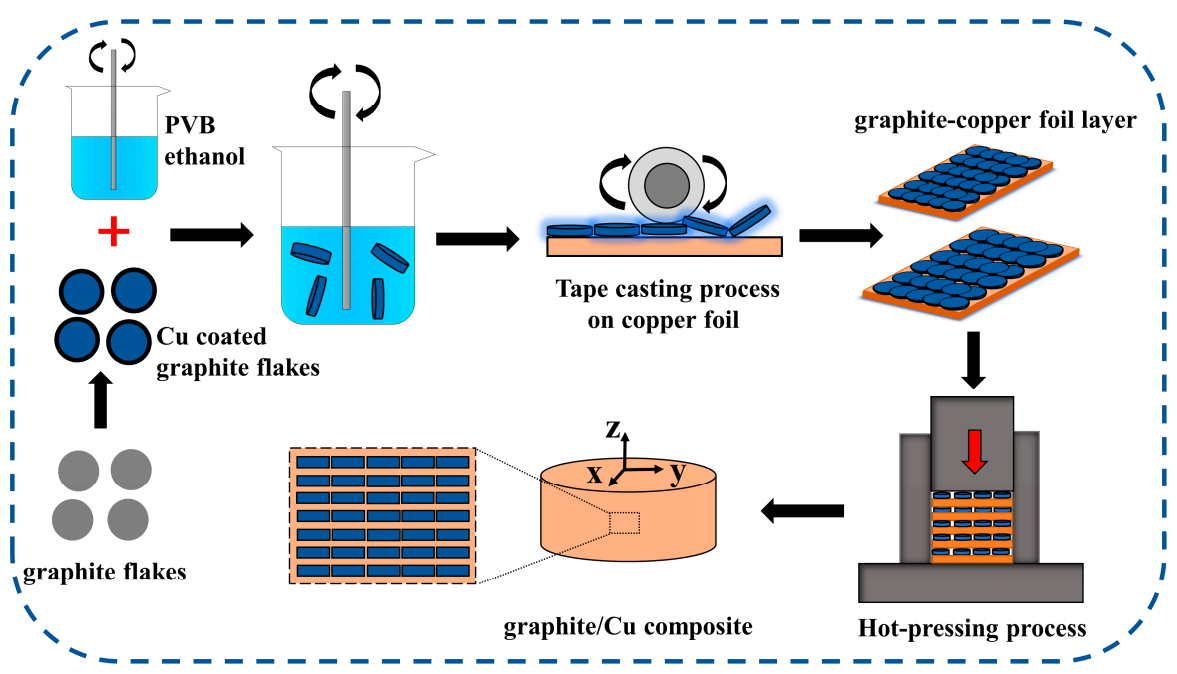

Figure 1. Schematic illustration of the preparation process of aligned graphite/Cu composites.

\subsection{Material Characterization}

The phase analysis of materials and obtained samples were characterized by X-ray diffraction (XRD, D8 ADVANCE DAVINCI, Karlsruhe, Germany) with monochromatic $\mathrm{Cu}-\mathrm{K} \alpha$ radiation. The thickness of the $\mathrm{Cu}$ coating on the surface of the GFs was characterized by focused ion beam (FIB, Auriga, Oberkochen, Germany). Morphology of materials and samples were observed by scanning electron microscope (SEM, FEI Quanta FEG 250, Hillsboro, OR, USA) employing accelerating voltages of 20 $\mathrm{kV}$, and the element distribution across the interface of GFs/Cu composites was analyzed by energy disperse spectroscopy (EDS). The thermal diffusivity $(\alpha)$ of composites was measured with laser flash apparatus (LFA467, Selb, Germany) at $25^{\circ} \mathrm{C}$. The density $(\rho)$ of composites was measured with solid densimeter (AKR-220SD, Shenzhen, China) at room temperature. The specific heat $\left(C_{p}\right)$ was characterized by differential scanning calorimetry (DSC 214, Selb, Germany) at $25^{\circ} \mathrm{C}$. The values of thermal conductivity $(\mathrm{K})$ were calculated by the equation:

$$
K=\alpha \times \rho \times C_{p}
$$

\section{Results and Discussion}

\subsection{Microstructure of Materials and Composites}

Figure 2a,b shows the morphologies of the raw GFs and Cu coated GFs, respectively. It is obvious to observe that a well coated layer was grown on the whole surface of the GFs. In order to get more information of the coating layer, the surface of coated graphite was peeled by FIB technique, as shown in Figure 2c. It could be found that a thickness of $1.8 \mu \mathrm{m}$ coating layer was covered on the surface of GFs. The SEM image of the coated GFs-Cu foil layer was shown in Figure 2d. The coated GFs were well oriented on the surface of the $\mathrm{Cu}$ foil and partly contacted with others.

To further determine the composition of the coating on the surface of the GFs, the XRD patterns of raw GFs and coated GFs were obtained and are shown in Figure 3, with a two heat angle scanning range of $20^{\circ} \sim 80^{\circ}$ and a scan speed of $4^{\circ} / \mathrm{min}$. The (002) and (004) crystal planes of the graphite phase are indexed in Figure 3a,b. In addition, it can be found that the other two peaks of (111) and (200) crystal planes of $\mathrm{Cu}$ exist in Figure 3b, which proves that the primary element of the coating layer is $\mathrm{Cu}$. The relative intensity of the $\mathrm{Cu}$ phase peaks is a little weak, because the $\mathrm{Cu}$ coating occupies low mass ratio of coated GFs. The in-plane and through-plane XRD patterns of the coated GFs/Cu foil composites are shown in Figure 3c,d, respectively. No other phases except $\mathrm{Cu}$ and graphite have been indexed, which indicates that the PVB-ethanol solution was well broken up or disappeared from the 
composites after the vacuum hot press process. The high relative intensity of graphite (002) crystal plane was indexed as the consequence of high orientation of GFs in Figure 3c.
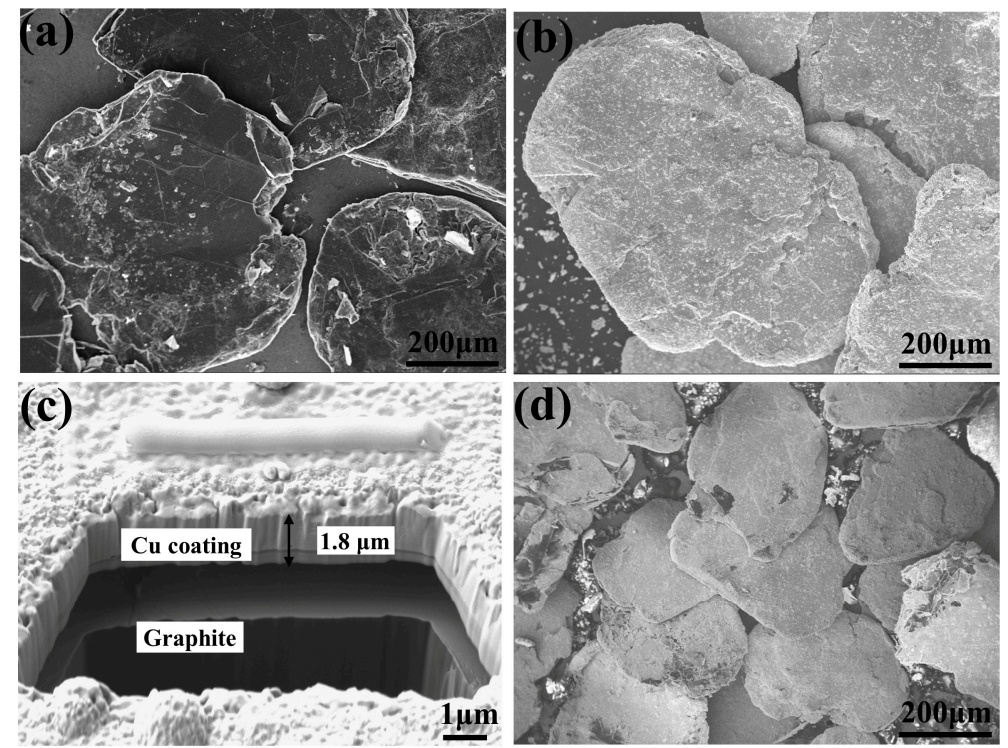

Figure 2. SEM images of (a) raw graphite flakes (GFs), (b) coated GFs, (c) coating on the surface of the GFs (d) coated GFs-Cu layer.
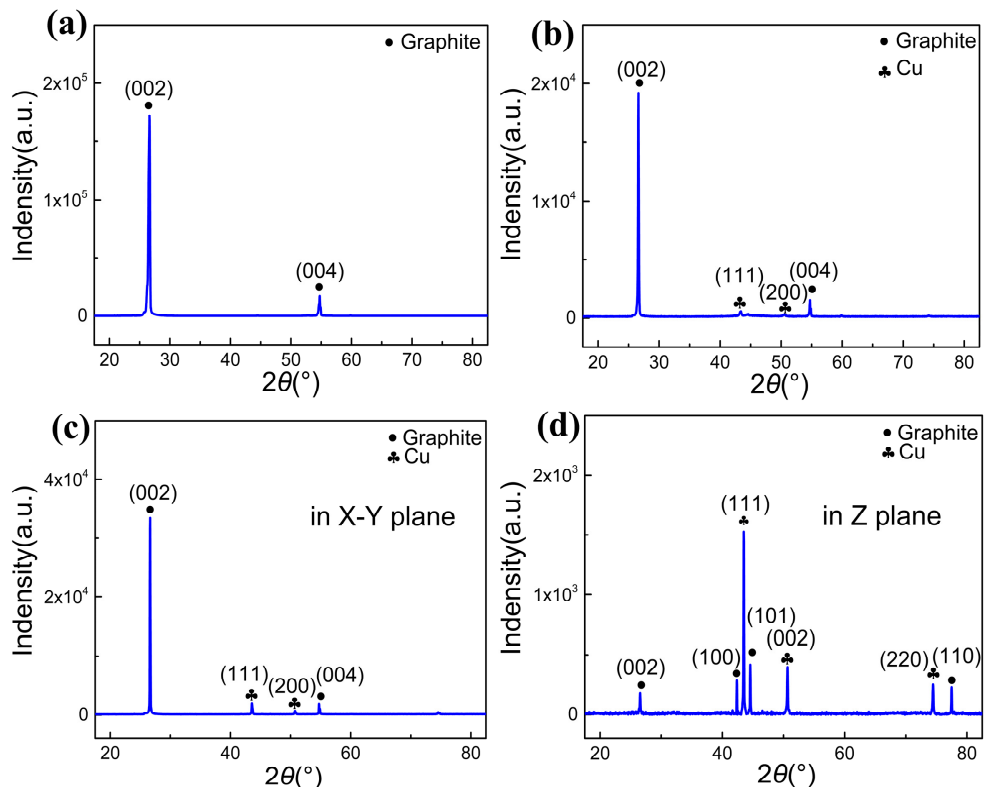

Figure 3. XRD patterns of (a) raw GFs, (b) coated GFs, (c) coated GFs/Cu composites in X-Y plane, and (d) coated GFs/Cu composites in Z plane.

Figure $4 \mathrm{a}, \mathrm{b}$ shows the typical side-view (in $\mathrm{Z}$ plane, $\mathrm{X}-\mathrm{Z}$ or $\mathrm{Y}-\mathrm{Z}$ plane) and top-view (in $\mathrm{X}-\mathrm{Y}$ plane) morphology of $70 \mathrm{vol} \% \mathrm{GFs} / \mathrm{Cu}$ composite. The dark region represents GFs while the light region represents the $\mathrm{Cu}$ matrix. As is shown in Figure $2 \mathrm{~d}$, the GFs were covering the surface of others in a certain area before the hot pressing process, which provided the possibility of long size continuous GFs. The size of the continuous dark region is much more than $500 \mu \mathrm{m}$, which is the average size of GFs in Figure 4a. The edges of GFs partly coincided with surroundings in Figure $4 b$, corresponding to Figure $2 \mathrm{~d}$. All these indicate that the single GF had connected with others to a certain degree, which is beneficial for forming high TC channels and improves the TC of the composite in the $\mathrm{X}-\mathrm{Y}$ plane. In order to explore the forms of continuous GFs, the high-magnification of corresponding regions in 
Figure 4a were provided in Figure 4a1-a3. Some GFs contacted with others by edges, which may cause bending deformation in Figure 4a1. Some GFs were clamped by pieces of GFs in Z plane direction and connected edges by the other GFs in the X-Y plane direction without edge deformation in Figure 4a2. The other GFs overlapped with each other, with about half of the surface area in Figure 4a3. Those connection ways contribute to the forming of a highly thermal network of GFs/Cu composites in the basis of the GFs. It also can be found that the GFs network was well packaged by $\mathrm{Cu}$ matrix in Figure $4 \mathrm{a}$,b. It might be that the $\mathrm{Cu}$ foil was in a semi-melted state at $1040{ }^{\circ} \mathrm{C}$ and the semi-melted $\mathrm{Cu}$ filled in the pores of the GFs network under $40 \mathrm{MPa}$ pressure. Figure 4c shows the interfacial micro-structure and EDS line-scan analysis of GFs and $\mathrm{Cu}$ matrix. The element analysis showed a high diffraction peak of $\mathrm{C}$ and low diffraction peak of $\mathrm{Cu}$ in the graphite phase, as is reversed in the $\mathrm{Cu}$ matrix. There was an excessive boundary of $\mathrm{C}-\mathrm{Cu}$ interface but no porosity or defects had been detected. Owing to the $\mathrm{Cu}$ coating on the surface of GFs, the GFs were not directly connected with each other. $\mathrm{Cu}$ coating on the surface of GFs provided transition area for the combination of $\mathrm{GFs}-\mathrm{Cu}$ and GFs-GFs.
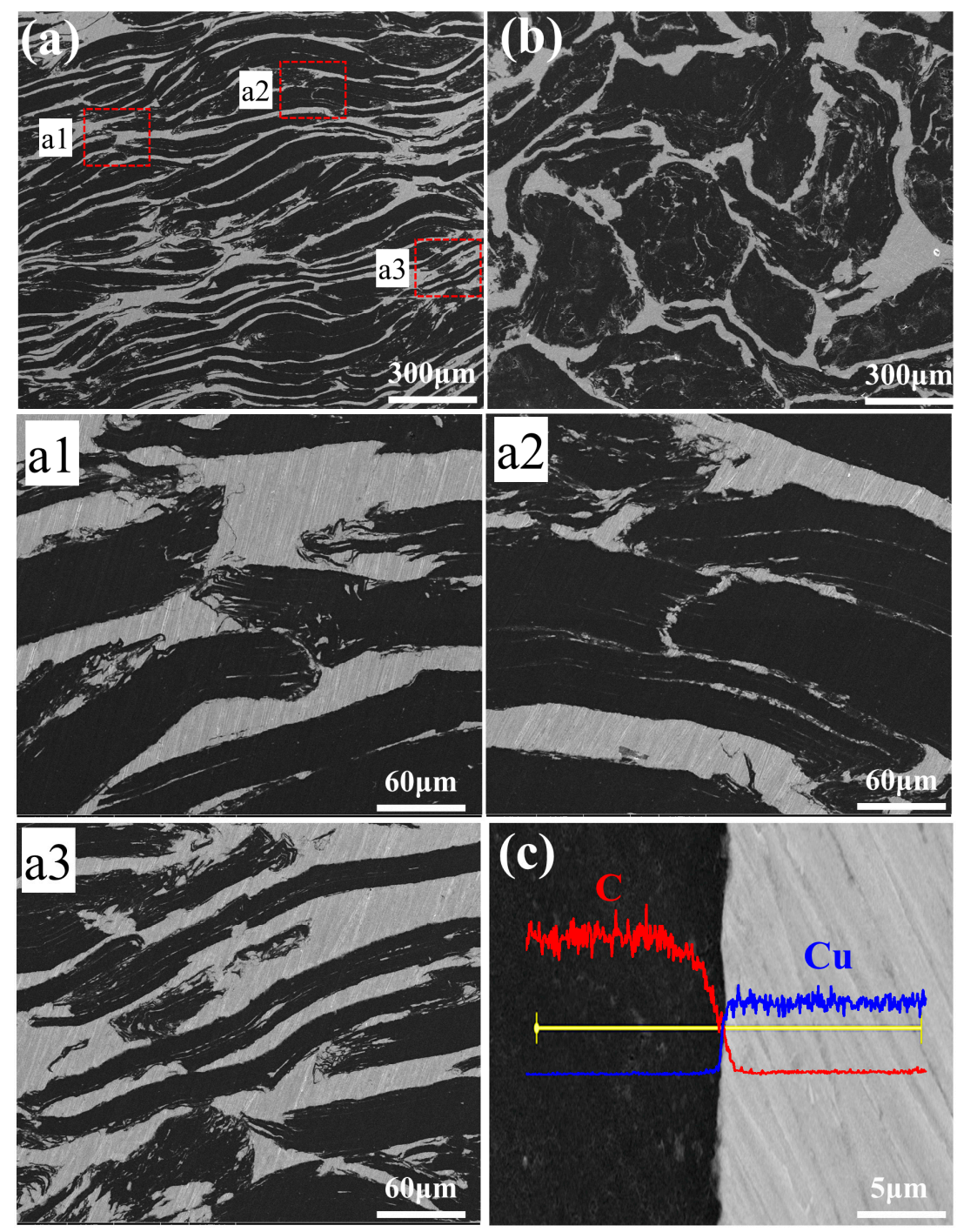

Figure 4. Morphology of GFs/Cu composites (a) in Z plane (a1, a2, a3 are the 5X magnification of corresponding regions in (a), (b) in X-Y plane; (c) interfacial micro-structure and EDS line-scan analysis. 


\subsection{Quantitative Analysis of GFs Alignment}

The alignment of GFs is significantly related to the thermal performance of composites because of its extremely anisotropic TC data. $\left\langle\cos ^{2} \beta>[30]\right.$ is used to align the degree of GFs, given by

$$
<\cos ^{2} \beta>=\frac{\int \rho(\beta) \cos ^{2} \beta \sin \beta d \beta}{\int \rho(\beta) \sin \beta d \beta}
$$

where $\beta$ is an acute angle of GFs high TC plane direction to the perpendicular direction of hot pressing axis, which is marked in Figure $5 \mathrm{a}$. The $\rho(\beta)$ is a statistical function used to describe the alignment degree of GFs in composites. When $\left\langle\cos ^{2} \beta>=1 / 3\right.$, the GFs alignment is close to random distribution. $<\cos ^{2} \beta>=0$ or $\left\langle\cos ^{2} \beta\right\rangle=1$ shows that the GFs alignment is absolutely parallel to hot-pressing axis or perpendicular to hot-pressing axis, respectively [31].

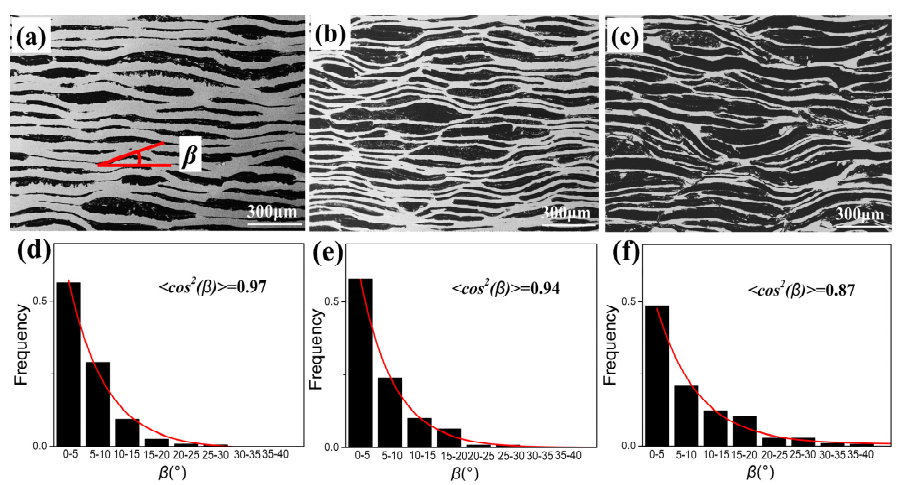

Figure 5. (a-c) SEM images of GFs/Cu composites in $\mathrm{Z}$ plane as the volume fraction of GFs is $30 \%, 50 \%$ and $70 \%$, respectively; (d-f) Corresponding frequency analysis of $\beta$ and function fitting of $\rho(\beta)$.

Figure $5 \mathrm{a}-\mathrm{c}$ shows the SEM images of GFs/Cu composites in the $\mathrm{Z}$ plane as the volume fraction of GFs being 30\%, 50\%, 70\%, respectively. Most of the GFs are well arranged in the composites with a consistent orientation. It can be found that there exists a highly paralleled structure where the GFs layer alternates with $\mathrm{Cu}$ layer in Figure 5a. As the volume fraction of GFs increased from 30\% to $70 \%$, the content of $\mathrm{Cu}$ layers was decreased and GFs layers network gradually appeared in Figure $5 b, c$. Figure $5 \mathrm{~d}-\mathrm{f}$ shows the frequency of $\beta$ distribution in different angel range and the fitted function $\rho(\beta)$. The $\beta$ and $\rho(\beta)$ were obtained by the procedure as follows. At first, the length $(L)$ and angel $(\beta)$ of single GF in SEM images were replaced by black lines with similar data. Then we got $L$ and $\beta$ data information by calculating these black lines. Finally, the $\rho(\beta)$ function was fitted with the obtained $\beta$ data by the ExpDec1 function derived from nonlinear curve fit procedure, given by

$$
\rho(\beta)=A_{1} e^{\left(-\beta / t_{1}\right)}+y_{0}
$$

where $A_{1}, t_{1}, y_{0}$ are fitting parameters. The $<\cos ^{2} \beta>$ values of GFs/Cu composites with different GFs volume fraction can be obtained. Figure $5 \mathrm{~d}-\mathrm{f}$ and Table 1 show the frequency analysis of $\beta$ and function fitting of $\rho(\beta)$. Most of $\beta$ concentrates on $0 \sim 10^{\circ}$ and more than $90 \%$ of $\beta$ are less than $20^{\circ}$, further confirming the highly aligned GFs. Though the $\left\langle\cos ^{2} \beta>\right.$ values decreased from 0.97 to 0.87 as the volume fraction of GFs increased from $30 \%$ to $70 \%$, they are much larger than $1 / 3$. 
Table 1. Properties (GFs content and alignment degree, density, specific heat capacity thermal diffusion coefficient and thermal conductivity) of GFs/Cu composites.

\begin{tabular}{|c|c|c|c|c|c|c|c|}
\hline \multirow{2}{*}{$V_{g}(\%)$} & \multirow{2}{*}{$\rho\left(\mathrm{g} / \mathrm{cm}^{3}\right)$} & \multirow{2}{*}{$C_{p}(\mathrm{~J} /(\mathrm{g} \cdot \mathrm{K}))$} & \multicolumn{2}{|c|}{$\alpha\left(\mathrm{mm}^{2} / \mathrm{s}\right)$} & \multicolumn{2}{|c|}{$\mathrm{TC}(\mathrm{W} /(\mathrm{m} \cdot \mathrm{K}))$} & \multirow{2}{*}{$<\cos ^{2} \beta>$} \\
\hline & & & $X-Y$ & $\mathbf{Z}$ & $\mathrm{X}-\mathrm{Y}$ & $\mathbf{Z}$ & \\
\hline 30 & 6.831 & 0.421 & 175 & 33 & 503 & 95 & 0.97 \\
\hline 40 & 6.142 & 436 & 217 & 27 & 581 & 72 & 0.96 \\
\hline 50 & 5.492 & 455 & 249 & 25 & 621 & 62 & 0.94 \\
\hline 60 & 4.825 & 478 & 296 & 23 & 683 & 53 & 0.91 \\
\hline 70 & 4.174 & 509 & 349 & 20 & 741 & 42 & 0.87 \\
\hline
\end{tabular}

\subsection{Thermal Properties and Modeling}

Table 1 depicts the thermal properties of GFs/Cu composites with different contents of GFs. The density apparently decreases with the increase of GFs content. The thermal diffusion coefficient in $X-Y$ plane sharply increases from 175 to $349 \mathrm{~mm}^{2} / \mathrm{s}$ as the volume fraction of GFs increases from $30 \%$ to $70 \%$, and the thermal diffusion coefficient in $\mathrm{Z}$ plane decreases from 33 to $20 \mathrm{~mm}^{2} / \mathrm{s}$ gently in reverse. According to Equation (1), the TC values of GFs/Cu composites are calculated in Table 1. The highly aligned GFs have an apparent effect on thermal conductivity of GFs/Cu composites. It can be seen that the TC is extremely high in $\mathrm{X}-\mathrm{Y}$ plane, while relatively low in $\mathrm{Z}$ plane, which indicates the anisotropic thermal properties of GFs/Cu composites. As with $70 \mathrm{vol} \% \mathrm{GFs}$, the TC of composites in X-Y plane and $\mathrm{Z}$ plane are 741 and $42 \mathrm{~W} /(\mathrm{m} \cdot \mathrm{K})$, respectively.

Herein, the $V_{g}$ is the volume fraction of GFs, $\rho, C_{p}, \alpha$, TC are the density, specific heat capacity, thermal diffusion coefficient and thermal conductivity of the GFs/Cu composites, $\left\langle\cos ^{2} \beta\right\rangle$ is the alignment degree of GFs in the GFs/Cu composites.

The TC of GFs/Cu composite can be predicted by layers-in- parallel model (i.e., parallel to the $X-Y$ plane) and layers-in-series model (i.e., perpendicular to the $X-Y$ plane) with the ideal orientation of GFs. The model is given by [32]

$$
\begin{gathered}
K_{C}^{L}=K_{g}^{L} V_{g}+K_{m}\left(1-V_{g}\right) \\
\frac{1}{K_{C}^{T}}=\frac{V_{g}}{K_{g}^{T}}+\frac{1-V_{g}}{K_{m}}
\end{gathered}
$$

where $K_{C}, K_{g}, K_{m}$ are the TC of composite, graphite and Cu matrix, respectively. The subscripts ' $L$ ', ' $T$ ' mean the direction parallel to the $X-Y$ plane and perpendicular to the $X-Y$ plane, respectively. Taking the interfacial thermal resistance of $\mathrm{Cu}$ and GFs into account, the analytical TC of reinforcement can be replaced by an "effective" TC, $K^{e f f}$, to improve the reliability of analysis. Considering the anisotropic $\mathrm{TC}$ of GFs, $K_{L}^{e f f}$ in $\mathrm{X}-\mathrm{Y}$ plane direction and $K_{T}^{e f f}$ in $\mathrm{Z}$ plane direction are given by [32]

$$
\begin{gathered}
K_{L}^{e f f}=\frac{K_{g}^{L}}{1+\frac{2 K_{g}^{L}}{h D}} \\
K_{T}^{e f f}=\frac{K_{g}^{T}}{1+\frac{2 K_{g}^{T}}{h t}}
\end{gathered}
$$

where $K_{L}, K_{T}$ are the TC of GFs in in-plane direction and through-plane direction. $D$ is the diameter of the GFs and $\mathrm{t}$ is the thickness of GFs. The average $D=500 \mu \mathrm{m}, \mathrm{t}=50 \mu \mathrm{m}$. $h$ is the interfacial thermal conductance. It can be calculated by the acoustic mismatch model (AMM), given by [33]

$$
h \cong \frac{1}{2} \rho_{m} C_{m} \frac{v_{m}^{3}}{v_{i}^{2}} \frac{\rho_{m} v_{m} \rho_{g} v_{g}}{\left(\rho_{m} v_{m}+\rho_{g} v_{g}\right)^{2}}
$$


where $\rho, C, v$ are the density, the specific heat capacity and phonon velocity, respectively. The subscripts of ' $m$ ', ' $g$ ' represent $\mathrm{Cu}$ matrix and graphite in this article, respectively. The material parameters for calculating $h$ are given in Table 2 and we obtained $K_{L}^{e f f}=880 \mathrm{~W} /(\mathrm{m} \cdot \mathrm{K}), K_{T}^{\text {eff }}=36 \mathrm{~W} /(\mathrm{m} \cdot \mathrm{K}), h=2.93 \times$ $10^{7} \mathrm{~W} /\left(\mathrm{m}^{2} \cdot \mathrm{K}\right)$.

Table 2. Material parameters for theoretical calculation.

\begin{tabular}{|c|c|c|c|c|c|}
\hline Material & Density $\left(\mathrm{g} / \mathrm{cm}^{3}\right)$ & Specific Heat Capacity $(\mathrm{J} /(\mathrm{g} \cdot \mathrm{K}))$ & Phonon Velocity (m/s) & Thermal Conductivity $(\mathrm{W} /(\mathrm{m} \cdot \mathrm{K}))$ & References \\
\hline Graphite & 2.260 & 0.710 & 14800 & $\begin{array}{c}1000^{X-Y} \\
38^{Z}\end{array}$ & [34] \\
\hline $\mathrm{Cu}$ & 8.900 & 0.385 & 2500 & 380 & [35] \\
\hline
\end{tabular}

Considering the GFs alignment and interfacial thermal resistance, the anisotropic TC data of GFs/Cu composite are deeply investigated by the effective medium approximation (EMA) model [30] with laminated flat plate reinforcement. Similar to aligned graphene composites [31], the calculation of $\mathrm{TC}$ of composites in $\mathrm{X}-\mathrm{Y}$ plane can be replaced by:

$$
K_{C}^{L}=K_{m}\left\{\frac{2+V_{g} \gamma_{L}\left(1+<\cos ^{2} \beta>\right)}{2-V_{g} \gamma_{T}\left(1-<\cos ^{2} \beta>\right)}\right\}
$$

with

$$
\begin{aligned}
& \gamma_{L}=\frac{K_{L}^{e f f}-K_{m}}{K_{m}} \\
& \gamma_{T}=\frac{K_{L}^{e f f}-K_{m}}{K_{L}^{e f f}}
\end{aligned}
$$

We obtained $\gamma_{L}=1.316, \gamma_{T}=0.568$ and $K_{C}^{L}$ can be calculated. The values of TC in $Z$ plane can be calculated by Equations (5) and (7). The TC model of GFs/Cu composites is shown in Figure 6.

Figure 6 shows the comparison on TC of different GFs/Cu composites. The raw GFs/Cu composites, $\mathrm{B}_{4} \mathrm{C}$ coated GFs/Cu composites [23] and SiC coated GFs/Cu composites [24] were fabricated by powder metallurgy method in an vacuum hot pressing furnace, with the GFs contents of 40 70 vol\%. As shown in Figure $6 \mathrm{a}$, the $\mathrm{B}_{4} \mathrm{C}$ coated GFs/Cu composites and $\mathrm{SiC}$ coated GFs/Cu composites exhibit lower TC than that of GFs/Cu composites. The TC of $\mathrm{B}_{4} \mathrm{C}$ coated $\mathrm{GFs} / \mathrm{Cu}$ composites and $\mathrm{SiC}$ coated $\mathrm{GFs} / \mathrm{Cu}$

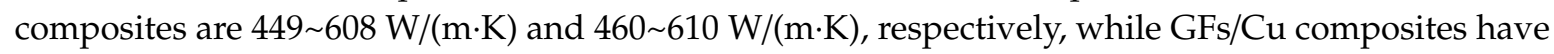
$477 \sim 676 \mathrm{~W} /(\mathrm{m} \cdot \mathrm{K})$. It indicates that even if coatings enhanced the interfacial binding strength of GFs and $\mathrm{Cu}$, it may not help to increase the TC of composites, for the interface thermal resistance of 'GFs-coatings- $\mathrm{Cu}^{\prime}$ is higher than 'GFs-Cu'. Therefore, $\mathrm{Cu}$ coating was introduced in this work by electroless plating to keep the balance of interfacial binding strength and interface thermal resistance in the GFs/Cu composites. As a result, the TC of aligned GFs/Cu composites (our work) reaches $503 \sim 683 \mathrm{~W} /(\mathrm{m} \cdot \mathrm{K})$ with the volume fraction of 30 60\%, which is slightly higher than GFs/Cu composites (Reference 23) with GFs content of $40 \sim 70 \%$. When the volume fraction of GFs increases to $70 \%$, the aligned GFs/Cu composites exhibits a high TC value of $741 \mathrm{~W} /(\mathrm{m} \cdot \mathrm{K})$. In Figure $6 \mathrm{~b}$, those different $\mathrm{GFs} / \mathrm{Cu}$ composites have a close thermal performance in $\mathrm{Z}$ plane. The TC values of raw $\mathrm{GFs} / \mathrm{Cu}$ composites, $\mathrm{B}_{4} \mathrm{C}$ coated GFs/Cu composites, $\mathrm{SiC}$ coated GFs/Cu composites and our work are 74 40, $71 \sim 40,77 \sim 36$ and 72 42 W/(m.K), respectively, with GFs content from 40 to $70 \mathrm{vol} \%$. This indicates that interfacial problems and alignment of GFs have a limiting influence on the Z-plane TC of GFs/Cu composites.

The anisotropic thermal properties of GFs (with in-plane TC of $1000 \mathrm{~W} /(\mathrm{m} \cdot \mathrm{K}$ ) and through-plane $\mathrm{TC}$ of $38 \mathrm{~W} /(\mathrm{m} \cdot \mathrm{K})$ ) causes the anisotropic TC of GFs/Cu composites. The value of anisotropy (VA) can be used to evaluate the alignment degree of GFs in composites, which is the ratio of TC in parallel to high thermal transfer direction $(X-Y$ plane) and perpendicular to high thermal transfer direction $(Z$ 
plane). As the volume fraction of GFs increases up to $70 \%$, the VA of GFs/Cu composites and our high aligned GFs/Cu composites is 16.90 and 17.64 , respectively. The result confirms the superiority of our work in controlling the alignment of GFs in composites.
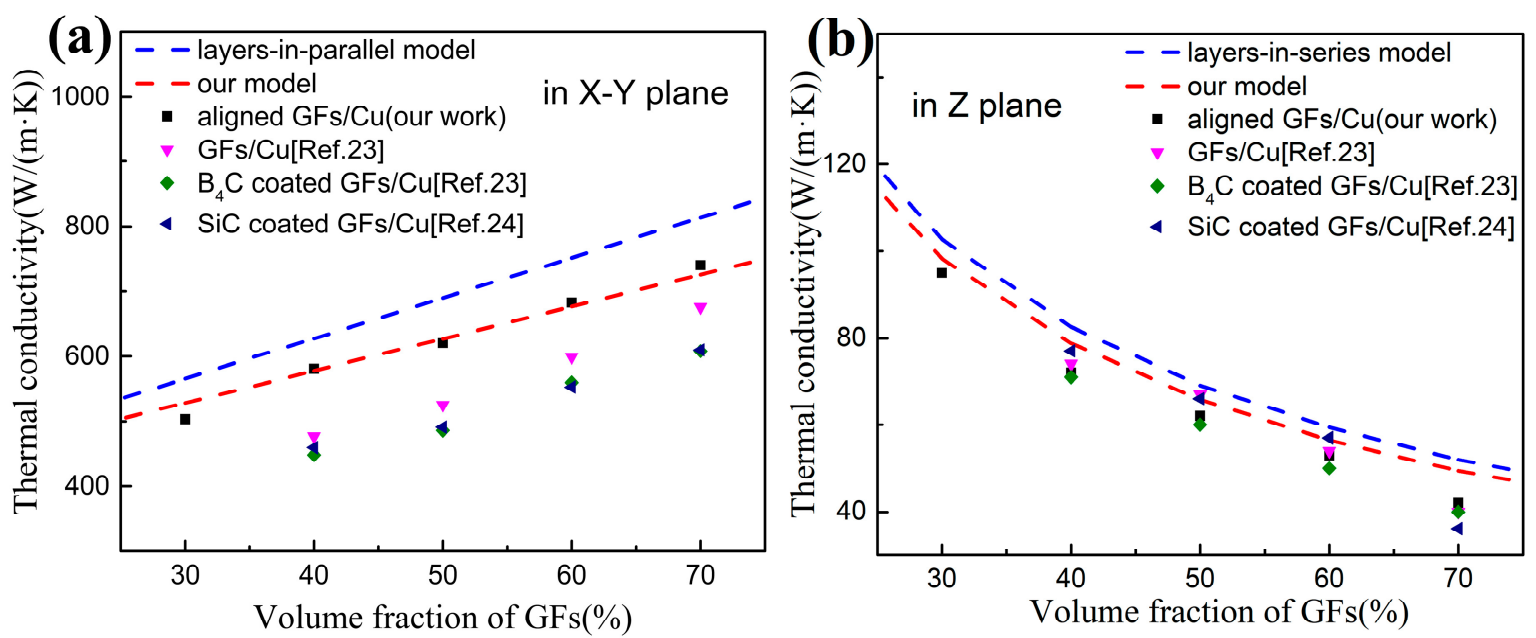

Figure 6. The thermal conductivity of GFs/Cu composites (a) in X-Y plane, (b) in Z plane.

\section{Conclusions}

In conclusion, ultrahigh thermal conductivity of aligned graphite flakes/Cu foil composites were fabricated by vacuum hot pressing process. The thermal conductivity of highly aligned graphite flakes/copper composites exhibited extremely anisotropy in the in-plane and through-plane. As the volume fraction of graphite flakes increased from $30 \%$ to $70 \%$, the in-plane thermal conductivity was ultrahigh and increased from 503 to $741 \mathrm{~W} /(\mathrm{m} \cdot \mathrm{K})$, while it decreased in the through-plane, which decreased from 95 to $42 \mathrm{~W} /(\mathrm{m} \cdot \mathrm{K})$. The alignment of graphite flakes and interfacial thermal resistance were taken into account to modify the thermal conductivity model for graphite/copper composites. The fabrication and modeling also suit other graphite flakes/metal matrix composites. The advanced composites can be realized to help cool modern electronics in the near future.

Author Contributions: F.Z. did the major experiment, wrote and revised the manuscript. H.M. helped in making the composite samples. C.X., J.Y., and N.J. supervised the project. J.Y. and C.-T.L. helped in the discussion and English editing. C.X. and N.J. provided the idea and polished the manuscript. All authors have read and agreed to the published version of the manuscript.

Funding: This research was funded by National Natural Science Foundation of China, grant number 51501209 and Ningbo Natural Science Foundation, grant number 2017A610010.

Conflicts of Interest: The authors declare no conflict of interest.

\section{References}

1. Mallik, S.; Ekere, N.; Best, C.; Bhatti, R. Investigation of thermal management materials for automotive electronic control units. Appl. Therm. Eng. 2011, 31, 355-362. [CrossRef]

2. Qu, X.H.; Zhang, L.; Wu, M.; Ren, S.B. Review of metal matrix composites with high thermal conductivity for thermal management applications. Prog. Nat. Sci. Mater. Int. 2011, 21, 189-197. [CrossRef]

3. Shu, S.; Yang, H.; Tong, C.; Qiu, F. Fabrication of TiCx-TiB(2)/Al Composites for Application as a Heat Sink. Materials 2016, 9, 642. [CrossRef] [PubMed]

4. Wu, D.; Huang, C.; Wang, Y.; An, Y.; Guo, C. Utilization of SiC and Cu Particles to Enhance Thermal and Mechanical Properties of Al Matrix Composites. Materials 2019, 12, 2770. [CrossRef] [PubMed]

5. Chu, K.; Wang, X.H.; Li, Y.B.; Huang, D.J.; Geng, Z.R.; Zhao, X.L.; Liu, H.; Zhang, H. Thermal properties of graphene/metal composites with aligned graphene. Mater. Des. 2018, 140, 85-94. [CrossRef]

6. Han, X.; Huang, Y.; Zhou, S.; Sun, X.; Peng, X.; Chen, X. Effects of graphene content on thermal and mechanical properties of chromium-coated graphite flakes/Si/Al composites. J. Mater. Sci. 2017, 29, 4179-4189. [CrossRef] 
7. Chen, J.K.; Huang, I.S. Thermal properties of aluminum-graphite composites by powder metallurgy. Compos. Part B Eng. 2013, 44, 698-703. [CrossRef]

8. Xue, C.; Bai, H.; Tao, P.F.; Wang, J.W.; Jiang, N.; Wang, S.L. Thermal conductivity and mechanical properties of flake graphite/Al composite with a SiC nano-layer on graphite surface. Mater. Des. 2016, 108, 250-258. [CrossRef]

9. Saadallah, S.; Cablé, A.; Hamamda, S.; Chetehouna, K.; Sahli, M.; Boubertakh, A.; Revo, S.; Gascoin, N. Structural and thermal characterization of multiwall carbon nanotubes (MWCNTs)/aluminum (Al) nanocomposites. Compos. Part B Eng. 2018, 151, 232-236. [CrossRef]

10. Kim, Y.S.; Kim, J.K.; Jeon, E.S. Effect of the Compounding Conditions of Polyamide 6, Carbon Fiber, and $\mathrm{Al}_{2} \mathrm{O}_{3}$ on the Mechanical and Thermal Properties of the Composite Polymer. Materials 2019, 12, 3047. [CrossRef]

11. Monje, I.E.; Louis, E.; Molina, J.M. Interfacial nano-engineering in Al/diamond composites for thermal management by in situ diamond surface gas desorption. Scr. Mater. 2016, 115, 159-163. [CrossRef]

12. Lindsay, L.; Broido, D.A.; Mingo, N. Diameter dependence of carbon nanotube thermal conductivity and extension to the graphene limit. Phys. Rev. B 2010, 82, 161402. [CrossRef]

13. Chang, C.W.; Fennimore, A.M.; Afanasiev, A.; Okawa, D.; Ikuno, T.; Garcia, H.; Li, D.; Majumdar, A.; Zettl, A. Isotope effect on the thermal conductivity of boron nitride nanotubes. Phys. Rev. Lett. 2006, 97, 085901. [CrossRef] [PubMed]

14. Emmerich, F.G. Young's modulus, thermal conductivity, electrical resistivity and coefficient of thermal expansion of mesophase pitch-based carbon fibers. Carbon 2014, 79, 274-293. [CrossRef]

15. Balandin, A.A.; Ghosh, S.; Bao, W.; Calizo, I.; Teweldebrhan, D.; Miao, F.; Lau, C.N. Superior Thermal Conductivity of Single-Layer Graphene. Nano Lett. 2008, 8, 902-907. [CrossRef]

16. Balandin, A.A. Thermal properties of graphene and nanostructured carbon materials. Nat. Mater. 2011, 10, 569-581. [CrossRef]

17. Norley, J. The role of natural graphite in electronics cooling. Electron. Cool. 2001, 7, 50-51.

18. Yuan, G.; Li, X.; Dong, Z.; Westwood, A.; Cui, Z.; Cong, Y.; Du, H.; Kang, F. Graphite blocks with preferred orientation and high thermal conductivity. Carbon 2012, 50, 175-182. [CrossRef]

19. Jiang, L.; Wang, P.; Xiu, Z.; Chen, G.; Lin, X.; Dai, C.; Wu, G. Interfacial characteristics of diamond/aluminum composites with high thermal conductivity fabricated by squeeze-casting method. Mater. Charact. 2015, 106, 346-351. [CrossRef]

20. Wang, P.; Xiu, Z.; Jiang, L.; Chen, G.; Lin, X.; Wu, G. Enhanced thermal conductivity and flexural properties in squeeze casted diamond/aluminum composites by processing control. Mater. Des. 2015, 88, 1347-1352. [CrossRef]

21. Naddaf, A.; Zeinali Heris, S. Experimental study on thermal conductivity and electrical conductivity of diesel oil-based nanofluids of graphene nanoplatelets and carbon nanotubes. Int. Commun. Heat Mass 2018, 95, 116-122. [CrossRef]

22. Li, N.; Wang, L.; Dai, J.; Wang, X.; Wang, J.; Kim, M.J.; Zhang, H. Interfacial products and thermal conductivity of diamond/Al composites reinforced with ZrC-coated diamond particles. Diam. Relat. Mater. 2019, 100, 107565. [CrossRef]

23. Bai, H.; Xue, C.; Lyu, J.L.; Li, J.; Chen, G.X.; Yu, J.H.; Lin, C.T.; Lv, D.J.; Xiong, L.M. Thermal conductivity and mechanical properties of flake graphite/copper composite with a boron carbide-boron nano-layer on graphite surface. Compos. Part A Appl. Sci. Manuf. 2018, 106, 42-51. [CrossRef]

24. Zhu, Y.; Bai, H.; Xue, C.; Zhou, R.; Xu, Q.; Tao, P.; Wang, C.; Wang, J.; Jiang, N. Thermal conductivity and mechanical properties of a flake graphite/Cu composite with a silicon nano-layer on a graphite surface. RSC Adv. 2016, 6, 98190-98196. [CrossRef]

25. Liu, Q.; He, X.-B.; Ren, S.-B.; Zhang, C.; Ting-Ting, L.; Qu, X.H. Thermophysical properties and microstructure of graphite flake/copper composites processed by electroless copper coating. J. Alloy. Compd. 2014, 587, 255-259. [CrossRef]

26. Sohn, Y.; Han, T.; Han, J.H. Effects of shape and alignment of reinforcing graphite phases on the thermal conductivity and the coefficient of thermal expansion of graphite/copper composites. Carbon 2019, 149, 152-164. [CrossRef] 
27. Zhou, C.; Huang, W.; Chen, Z.; Ji, G.; Wang, M.L.; Chen, D.; Wang, H.W. In-plane thermal enhancement behaviors of $\mathrm{Al}$ matrix composites with oriented graphite flake alignment. Compos. Part B Eng. 2015, 70, 256-262. [CrossRef]

28. Li, W.; Liu, Y.; Wu, G. Preparation of graphite flakes/Al with preferred orientation and high thermal conductivity by squeeze casting. Carbon 2015, 95, 545-551. [CrossRef]

29. Xu, C.; Wu, G.; Liu, Z.; Wu, D.; Meek, T.; Han, Q. Preparation of copper nanoparticles on carbon nanotubes by electroless plating method. Mater. Res. Bull 2004, 39, 1499-1505. [CrossRef]

30. Nan, C.-W.; Birringer, R.; Clarke, D.R.; Gleiter, H. Effective thermal conductivity of particulate composites with interfacial thermal resistance. J. Appl. Phys. 1997, 81, 6692-6699. [CrossRef]

31. Chu, K.; Wang, X.H.; Wang, F.; Li, Y.-b.; Huang, D.J.; Liu, H.; Ma, W.L.; Liu, F.X.; Zhang, H. Largely enhanced thermal conductivity of graphene/copper composites with highly aligned graphene network. Carbon 2018, 127, 102-112. [CrossRef]

32. Zhou, C.; Ji, G.; Chen, Z.; Wang, M.; Addad, A.; Schryvers, D.; Wang, H. Fabrication, interface characterization and modeling of oriented graphite flakes/Si/Al composites for thermal management applications. Mater. Des. 2014, 63, 719-728. [CrossRef]

33. Molina, J.; Prieto, R.; Narciso, J.; Louis, E. The effect of porosity on the thermal conductivity of Al-12wt.\% $\mathrm{Si} / \mathrm{SiC}$ composites. Scr. Mater. 2009, 60, 582-585. [CrossRef]

34. Ueno, T.; Yoshioka, T.; Ogawa, J.I.; Ozoe, N.; Sato, K.; Yoshino, K. Highly thermal conductive metal/carbon composites by pulsed electric current sintering. Synth. Met. 2009, 159, 2170-2172. [CrossRef]

35. Swartz, E.T.; Pohl, R.O. Thermal boundary resistance. Rev. Mod. Phys. 1989, 61, 605-668. [CrossRef]

(C) 2019 by the authors. Licensee MDPI, Basel, Switzerland. This article is an open access article distributed under the terms and conditions of the Creative Commons Attribution (CC BY) license (http://creativecommons.org/licenses/by/4.0/). 